\title{
Adult MOOC Learners as Self-Directed: Perceptions of Motivation, Success, and Completion
}

\author{
Jamie Loizzo \\ University of Nebraska-Lincoln \\ Peggy A. Ertmer, William R. Watson \& Sunnie Lee Watson \\ Purdue University
}

\begin{abstract}
Despite the increased attention given to MOOCs over the last four years, learners' voices have been noticeably absent. This virtual ethnographic study was designed to examine the experiences of 12 adult learners with bachelors' and masters' degrees, enrolled in a four-week MOOC on the topic of human trafficking. Through the lenses of self-directed learning and self-determination theories, we were interested in investigating learners' motivations for enrolling in the MOOC, their perceptions of success and completion, and barriers encountered while trying to complete the MOOC. Reasons for enrollment varied from personal enjoyment to professional development, and differing definitions emerged regarding completion or success in a MOOC. Implications of this study include a proposed conceptual framework of adult learner MOOC motivations and goals, which may inform the intentional instructional design of MOOCs to better meet adults' self-directed learning needs. Results also pointed to the potential for social science MOOCs to promote activism and attitudinal and social change.
\end{abstract}

Keywords: MOOC, distance education, adult learners, motivation, completion, virtual ethnography

Loizzo, Jamie, Ertmer, Peggy A., Watson, William R., \& Watson, Sunnie Lee (2017). Adults as self-directed and determined to set and achieve personal learning goals in MOOCs: learners' perceptions of MOOC motivation, success, and completion. Online Learning 21 (2) doi: 10.24059/olj.v21i2.889

\section{Introduction}

The primary purpose of Massive Open Online Courses (MOOCs) is currently debated among higher education administrators and professors as well as educational technology companies (Hollands \& Tirthali, 2014; Jenkins, 2013; Lombardi, 2013; Pappano, 2012; Selingo, 2014). Universities and MOOC providers such as Coursera, EdX, and Udacity continue to make 
headlines in major mainstream media such as The Wall Street Journal and Washington Post as well as academic outlets such as The Chronicle of Higher Education and Inside Higher Ed (Kolowich, 2013a; Korn \& Levitz, 2013; Luberecki, 2015; Thille, Mitchell, \& Stevens, 2015). Predominantly, the voices that permeate these reports are those of administrators, professors, and industry developers who analyze the designs, uses, and business models for MOOCs.

Although learners' voices are sometimes included in articles and research about MOOCs (Gose, 2012; Velestianos, 2013), they are still very rare. While statistical reports may demonstrate trends in learners' MOOC experiences, they fail to provide more nuanced insights from the learners themselves. For example, statistics have shown that thousands of learners from around the world enroll in MOOCs to learn about a diversity of topics from a variety of institutions, and that the majority of those learners already hold higher education degrees (Nesterko, 2014a). Furthermore, these adult learners typically do not complete the courses (Khalil \& Ebner 2014; Park \& Choi, 2009). What the statistics cannot tell us, however, are learners' motivations for enrolling in these courses and their individual reasons for completing or not completing the MOOCs.

This research investigated educated adult learners' experiences in a MOOC about human trafficking, as well as their perceptions of MOOC motivation, success, and completion. It is important to understand how learners view and experience MOOCs, especially given that one of the initial reasons for their development was to make higher education more accessible to learners around the world. Insight into learners' MOOC experiences has the potential to influence future instructional designs and pedagogical approaches applied to these massive global learning environments. This study may also be of interest to educators and instructional designers who develop and facilitate distance education environments such as graduate-level courses for credit and non-credit, communities of practice, and social learning networks for adult learners. While the focus of this research is specifically on the MOOC environment, insights gained from this study into adults' online experiences may be applicable when considering learners' motivation, success, and completion in other online learning environments. In the following section, we review literature relevant to MOOC design, demographics, self-directed learning theory, and self-determination learning theory that informed this study.

\section{Literature Review}

\section{MOOC Designs and Demographics}

MOOCs have been said to "disrupt" higher education because they challenge traditional educational and business models in which learners pay for credit hours to attend lectures given by professors within the physical walls of universities (Haber, 2014; Selingo, 2014). While distance education has already pushed the boundaries of traditional learning environments, MOOCs have amplified distance education on a massive global level. Thousands of learners from around the world have enrolled in courses from prestigious universities, industry, and nonprofit organizations to learn about a variety of topics (Selingo, 2014).

In general, learners navigate two types of MOOC instructional design models: cMOOCs and xMOOCs. Early MOOCs relied on connectivist pedagogy and are often referred to as cMOOCs (Liyanagunawardena et al., 2013; Rodriguez, 2012). Tschofen and Mackness (2012) 
emphasized that connectivism focuses more on the collective learning network than the autonomy of each individual learner. In a cMOOC model, learners form networks using social media tools to engage, not only with one another but also with the course content (Bell, 2011; Siemens \& Conole, 2011; Clarà \& Barberà, 2013). In contrast, xMOOC designs are more focused on content than social networks, promoting individualized learning through lecture videos, quizzes, and assignments. xMOOCs do not necessarily require learners to connect via social networking tools (Rodriguez, 2012). MOOC platform companies such as Coursera, edX, and Udacity emerged from the xMOOC model.

While MOOC platform providers intended to open up education to everyone, quantitative enrollment data suggest that MOOC learners are predominantly adults who already possess postsecondary degrees. For example, data released by MOOC providers, HarvardX and MITx, indicated that the students enrolled in the companies' 17 MOOCs from fall 2012 to summer 2013 were typically adults, 26 years of age or older, who already had bachelor's degrees (Ho et al., 2014; Nesterko et al., 2014a; Nesterko et al., 2014b). While MOOCs reach a worldwide audience, adults with college degrees comprise the majority of enrolled learners.

In the case of Udacity, the company has made some adjustments to respond to the large numbers of adult professional MOOC learners. That is, Udacity has begun offering "nanodegrees" for a monthly fee for those adults who wish to develop new skills and/or earn certificates of completion in areas such as mobile app development (Udacity, 2015). While adult professionals may not have been the original target audience for MOOCs, it is important to examine this population to determine why these learners take MOOCs, what they experience, and how their experiences might inform the design of future MOOCs.

\section{Tension Over Completion Rates}

MOOCs have been criticized for their low completion rates. MOOC providers and higher education institutions have reported somewhat complicated and confusing statistics about learner completion rates that have left administrators and professors skeptical as to whether or not MOOCs are worth the effort and investment (Jenkins, 2013; Kolowich, 2013g). Data from several early Harvardx and MITx MOOCs showed that thousands of MOOC learners did not complete the courses and, in fact, that multiple MOOCs had completion rates lower than $15 \%$ (Ho et al., 2014). Jordan (2014) synthesized enrollment data ( $\mathrm{n}=91$ courses) and completion data $(n=39$ courses) across a variety of MOOCS to find a median enrollment of 42,844 learners and a median completion rate of $6.5 \%$. The conundrum of low completion rates in contrast with such large enrollment numbers has led some MOOC providers to question whether completion is the proper measurement of the learning and effectiveness of MOOCs (Koller, Ng, Do, \& Chen, 2013).

Coursera founder Daphne Koller and her team proposed moving away from completion rates as the standard measurement of success to one that focuses on learners' intentions. Koller et al. (2013) outlined three categories of MOOC learners: passive participants (watched/read content), active participants (completers), and community contributors (posted in discussion forums). Kizilcec and Schneider (2015) found that less than half (45\%) of the learners in their study of 14 MOOCs $(n=71,475)$ ever intended to earn a certificate. Rather, top reasons for enrolling in MOOCs included general interest and personal growth, job and academic relevance, 
and social engagement (Kizicec \& Schneider, 2015). Similarly, a content analysis of 21 blog posts from learners enrolled in at least one MOOC showed a variety of motivations, from investigating MOOC design and instruction to "a desire to explore, learn, and develop" (Zutshi, O'Hare, \& Rodafinos, 2013, pp. 224-225). This is consistent with Hew and Cheung's (2014) findings that the four main reasons to enroll in MOOCs included: (1) "They wanted to learn about a new subject or to increase their knowledge on something they learned before," (2) "They were curious about MOOC[s]," (3) They wanted a "personal challenge," and (4) "They wanted to get as many course certificates as possible" (p. 48).

De Barba, Kennedy, and Ainley (2016) surveyed 862 learners who persisted in the final three weeks of an economics MOOC and found a positive relationship between learner motivation, participation, and performance. The researchers recommended that MOOC activities be designed to dynamically engage learners who have diverse motivations and goals for participating in the course, which may not include completion. McAuley et al. (2010) also discussed learner differences in their definition of "MOOC" and acknowledged that learners determine their own levels of participation based on their "learning goals, prior knowledge and skills, and common interests" (p. 4). Oakley, Poole, and Nestor (2016) reported that learners are motivated to persist in those MOOCs that have "stickiness" factors such as relevant content, clear instructions, an engaging instructor, and a timetable that is manageable within adult learners' busy schedules.

\section{Self-Directed Learning and Self-Determination in MOOCs}

Given the type of adult learners commonly present in MOOCs (Nesterko et al., 2014a), a number of factors could influence levels of student motivation and participation in the massive online courses. Park and Choi (2009) noted that adults are often drawn to distance education because it offers a flexible and affordable way for them to fit learning into their busy schedules that revolve around work, family, and other responsibilities. The authors found that learner characteristics (gender, race, etc.) had little impact on online course performance, whereas external factors such as family, employer, and financial support had the potential to "interrupt learners' participation and persistence" (p. 215). The authors also discussed the importance of designing online courses that meet adult learners' needs, keep them motivated and socially integrated, and provide content and scenarios that apply to their everyday lives in order to maintain learner motivation and increase course completion and satisfaction rates (Park \& Choi, 2009).

Adults often participate in multiple social roles that are flexible and change over time. Those roles could potentially impact their reasons to engage in various learning experiences (Merriam \& Bierma, 2013). Learners can choose from a multitude of MOOCs and for a variety of reasons, and they can direct their own learning inside and across MOOC offerings. Selfdirected learning (SDL) theory can be drawn upon to better understand how adult learners navigate and experience MOOCs. SDL states that individual adults have the capacity to plan, navigate, and assess their own learning on the path to their personal learning goals (Hiemstra, 1994). Caffarella (as cited in Merriam \& Bierma, 2013) pointed out that adults may engage in SDL to educate themselves about a particular topic or issue in order to support or confront social justice and political causes. Self-directed adult learners may choose to learn on their own or in groups, and have the capacity to transfer learning from one context to another. SDL is largely 
comprised of learner goal setting, self-regulation of learning, and self-evaluation of learning (Theunissen \& Stubbé, 2014). Stubbé \& Theunissen (2008) identified the following elements of SDL that should be incorporated into a "ubiquitous environment" for adult learning: (1) learner control, (2) self-regulated learning strategies, (3) reflection, (4) interaction with the social environment, and (5) interaction with the physical world. The researchers reported that learning environments which allow for learner control and stimulate self-regulation, reflection, and interaction inside and outside of the learning environment are conducive for SDL.

The thread underpinning SDL is motivation: intrinsic and extrinsic. Schunk, Pintrich, and Meece (2008) defined motivation as "the process whereby goal-directed activity is instigated and sustained" (p. 378). Adults are described to be motivated to learn by internal factors such as "increased job satisfaction, self-esteem, and quality of life" (Cercone, 2008, p. 145). Cercone pointed out that while internal factors motivate adults, the external online learning environment must be favorable to fostering and promoting further motivation through thoughtful instructional design that includes social interactions within the course, content grounded in reality, reflection, and opportunities for SDL.

Closely connected to the self-regulation and motivational components of SDL is selfdetermination theory (SDT). SDT acknowledges the balance between internal (intrinsic) motivators, external (extrinsic) motivators, and amotivation (no intention to act) and how these dynamics interact within the immediate social context (Chen \& Jang, 2010; Hartnett et al., 2011). Hence, various motivators or lack of intention to act can influence participation and experiences in the immediate context of an online course (Hartnett et al., 2011). SDT states that humans intrinsically need to make their own choices to become knowledgeable and skillful within their extrinsic environments (Hartnett et al., 2011). Cercone (2008) wrote that an adult learner "should be seen as a whole person" and that adult online education is about "sensing, visualizing, perceiving, and learning informally with others" (pp. 151-152). Adult learners are known to have differing educational levels and interests in their lives (Cercone, 2008; Hartnett, George, \& Dron, 2011). Some adult learners need intense instruction and guidance, while others prefer to learn on their own and at their own pace. SDL and SDT consider adult learners to be autonomous with the need to choose their learning paths and goals. These theories should be further applied and investigated in the context of MOOCs, specifically in regards to top-down imposed completion criteria resulting in typically low MOOC completion rates. This review of literature about MOOC designs, demographics, completion rates, and SDL and SDT theories informed the development of research questions and methods to investigate adult learners' MOOC experiences in this study.

\section{Methods}

\section{Purpose of the Study}

The purpose of this research study was to gain a deeper understanding of the MOOC experiences of adult learners with bachelors' and masters' degrees, including their motivations for participation and their perceptions of MOOC success and completion. To date, published MOOC research studies have focused primarily on quantitative data such as general learner demographics, completion rates, and business models. Prior research has found very low completion numbers, yet adult learners continue to enroll and participate in a variety of courses. SDL theory and SDT suggest that adult learners have the capacity to set their own goals and 
regulate their own learning (Chen \& Jang, 2010; Theunissen \& Stubbé, 2014). Using these theories as a lens to examine adult learners' MOOC experiences, this study aimed to use qualitative methods to more deeply examine adult learners' motivations for participating in MOOCs and their perceptions of success and completion. The research questions were:

- What motivates adult learners with post-secondary degrees to participate in MOOCs?

- What are adult learners' perceptions of "success" in a MOOC?

- How does an adult learner define "completion" of a MOOC?

An additional research question emerged from the data:

- What perceived barriers prevent adult learners from being successful in MOOCs and achieving completion?

\section{Research Design}

This study used a descriptive qualitative design to examine student experiences more deeply (Esposito, 2012; Liyanagunawardena et al., 2013). Descriptive research "seeks to describe the aspect of social reality under investigation" (Hesse-Biber, 2017, p. 13). The first author engaged directly with adult MOOC learners using Internet-based research (IBR) methods. Typically, IBR consists of data collection from online analytics sources and communications. Broad and Joos (2004) used the term "online inquiry" to describe their qualitative studies of online communities. In this study, the online inquiry method of virtual ethnography was used to develop a thick description of adult learners' MOOC experiences. As a research method, virtual ethnography can "be used to develop an enriched sense of the meanings of the technology and cultures which enable it and are enabled by it" (Hine, 2000, p. 8). Thus, virtual ethnography is the study of the boundaries between the virtual and the real, the use of the Internet to form relationships and social communities, and the Internet's effects on people (Hine, 2000). Within this research, virtual ethnography methods were used to observe informants' MOOC participation, as well as direct contact and discussion with informants to make sense of their virtual and offline identities and experiences.

In fall 2014, the first researcher operated overtly in a MOOC titled Human Trafficking offered by a large Midwestern university. With permission secured from the MOOC instructor and instructional designer, participants were recruited via an email sent to all enrolled MOOC students. Researchers determined criteria for participation before launching the study, which included learners from all over the globe, between the ages of 25-70 years old, and with postsecondary degrees. Our initial recruitment survey sent to all MOOC learners had 671 responses filtered to 628 to eliminate incomplete entries and those that did not meet the criteria of adult learners with higher education degrees. From the participation and informed consent responses $(n=671)$, a stratified random sampling technique was used to identify potential research informants for this study. Potential participants were filtered into two groups based on gender, age, and education to randomly select 25 possible informants. A criterion of location in Indiana (the researchers' home state) was then applied to the two groups to randomly select 5 more potential informants. The 30 informants were then contacted with a response rate of 12 informants committed to participating. In addition, two informants emailed the researcher about 
their direct interest in participating and were also included in the study because they presented unique cases. One was a self-identified victim of human trafficking and the other was at the upper end of the targeted age range and worked to prevent human trafficking in Thailand. This totaled 14 informants for the study, although two of the informants did not complete the postinterview.

\section{Context and Informants}

The context for this research was the MOOC entitled Human Trafficking (HT) offered by a large Midwestern university through the Coursera platform. The HT MOOC enrolled 30,207 learners from 186 different countries. Of the total enrolled, 14,541 learners visited the course at least once. $34 \%$ of the enrolled learners had bachelor's degrees, $26 \%$ had master's degrees, and $4 \%$ had doctoral degrees. $62 \%$ of the learners were female and $37 \%$ were male. In order for learners to earn the Statement of Accomplishment in the HT MOOC, they were required to complete all quizzes and a public service announcement assignment (PSA) to earn $70 \%$ of the total 100 course points. Fourteen adult learners (six male, eight female) with post-secondary degrees (one with some college credits), between the ages of 25-70 and living in the United States, Thailand, China, and Moldova, were informants in this study. Therefore, the sampling procedures were both random and opportunistic to allow for the Indiana informants and two unique cases that emerged (Gerber, Abrams, Curwood, \& Magnifico, 2017).

Twelve of the fourteen informants completed the post-interview. While this could be considered a small sample size, qualitative research often focuses on small samples in order to enable rich data collection for a thorough understanding of a lived experience (Hesse-Biber, 2017). The fourteen informants in this study provided rich data via observations and interviews that gave insights into similarities and differences across adult learners' experiences. The goal was not to generalize, but to deeply investigate a small number of cases. The term "informants" is used here, as the adult learners in this study informed us of their perceptions of, and experiences in, the HT MOOC. In virtual ethnographic work, researchers establish relationships with informants, as informants provide access and inside information that researchers otherwise would not experience on their own (Schwandt, 2015). We worked with informants to coconstruct pseudonyms to protect their identities. The pseudonyms are representative of informants' backgrounds, ethnicities, and personalities.

\section{Data Collection and Analysis}

The first author participated overtly as a researcher in the four-week MOOC. Researcher positioning is considered crucial in studying online learning spaces (Gerber, Abrams, Curwood, \& Magnifico, 2017). The researcher can serve as an informant about the learning environment as well as an instrument in data collection and analysis (Gerber, et al., 2017). The first researcher was given "teaching assistant" access to the MOOC by the institutional provider in order to examine informants' MOOC activities. She embedded herself in the MOOC and maintained email contact with informants to gain deeper understanding of their backgrounds and MOOC experiences, made observations of course happenings and informant interactions, took weekly screen captures of course and informants' activities, and conducted post-interviews with informants via Skype. Twelve of the fourteen informants participated in the post-interviews which lasted approximately 60-90 minutes each. Interview questions specifically focused on the informants' motivations for enrollment and participation, their experiences within the MOOC, 
and their perceptions of success and completion. Sample interview protocol questions included: Why did you take this MOOC? (Motivation?) How would you define "success" within a MOOC? (Success?) What does it mean to complete a MOOC? (Completion?)

The first step of data analysis included a review of video-recorded interviews, transcription of interviews to text, and a review of researcher field notes and email conversations with informants. Interview transcriptions and field notes were coded using open, focused, and axial coding techniques for emerging patterns (Miles et al., 2013). Repeated occurrences in the data from the first round of coding were grouped into categories for round two coding and, ultimately, themes emerged in the final round of coding. It is through this inductive coding process that themes such as "barriers to MOOC success and completion" emerged. The data were also coded deductively. That is, learner responses to specific interview questions related to motivation, success, and completion were grouped into pre-defined categories specifically matched to research questions and then tallied. Additional virtual ethnographic data analysis steps included constant comparison of the codes that emerged from the interview and field note data to the data from course artifacts and observations in order to achieve data triangulation (Hine, 2000). For instance, an informant described her experience in a MOOC discussion board in the interview. Based on the interview description, the informant's discussion board post was located, analyzed, and compared to her interview transcript. To make sense of the understanding, interconnections, and relationships of emerged themes, we used Miles et al.'s recommended methods for descriptive analysis to develop a conceptual map concerning informants' perceptions of motivation, success, completion, and barriers.

To address trustworthiness in data collection and analysis, multiple steps were followed. Researcher reflexivity, via observational and reflective journaling, was maintained for transparent understanding of researcher positioning in the virtual environment and to mitigate potential bias (Gerber, 2017). After each $\log$ in, the first author spent 15-30 minutes journaling about her observations, email interactions with informants, her thoughts and feelings, and emerging questions to ask informants. Peer debriefing throughout the data coding process was also used to ensure research team members arrived at a consistent and shared understanding of data collection procedures, analysis, and final thematic and conceptual framework findings (Schwand, 2015). Member-checking procedures were also followed to confirm research results with informants (Schwandt, 2015), who confirmed that the proposed adult learner MOOC conceptual framework reflected their experiences. Results are reported using "thick description" (Denzin, 1989) in order to provide rich details and specific examples from informants' experiences. Schwandt (2015) noted that a hallmark of thick description is not only to report data, but also to provide initial interpretations. This study presents detailed quotes and observations to describe results, and proposes a conceptual framework of the adult learner MOOC experience as a means to provide thick description of our research results.

\section{Results}

Post-interviews, informants' course artifacts and observations were coded for themes related to adult learners' MOOC motivations and perceptions of success and completion. The following sections highlight the similarities and differences among the informants' MOOC experiences and perceptions. An additional theme, barriers to MOOC success and completion, also emerged from the data and is presented in the results. 


\section{Motivation}

Twelve informants described eight factors as influential in their motivation to enroll and participate in the HT MOOC. From the first round of open-coding, codes such as "content interest" and "information retrieval" emerged. During additional rounds of coding, researchers compared these factors across informants' cases to gauge frequency of occurrence in order to better understand which factors were most prevalent.

The informants were specifically asked to provide their reasons for enrolling and participating in the HT MOOC; all twelve identified being motivated by the HT content and having a desire to learn more about it. Some informants highlighted specific personal interest in the content. For example, Isabella wanted to understand how HT impacts adoption around the world, as she had adopted her daughter in India. She explained, "I'm an adoptive mother, and we adopted when we were in India, and I was used as a spy on the market of illegal adoptions." Other informants, like Sean, were motivated to learn more about HT due to external factors. Sean had watched a popular movie about HT and was motivated to learn more. Torrence expressed an interest in expanding his current understanding of trafficking and to build upon his background and prior learning in the field of criminal justice. He said, "[It was] just something that interested me. In any of my coursework in school, we didn't cover anything like sex trafficking or get into that. So, knowledge of that is kind of what motivated me to do that."

The third most prevalent motivator was professional development or volunteerism. Mimi and Claudia both worked with organizations that sought to prevent HT, while Regina, a teacher in an alternative high school, wanted to incorporate what she learned into her teaching about slavery in modern times:

The human trafficking is interesting, particularly because I'm at an alternative high school and those kids have, every one of them has a different story as to how they've gotten where they've gotten, and some of those stories aren't all that happy. So, it's kind of one of those things that I think teachers, that we, that we really need to be aware of. (Regina, Skype 12, 2015)

Four others, Blake, Elizabeth, Ed, and Joseph, were currently volunteers at different anti-HT organizations around the world. Blake described his motivation. "I take pretty much any class that has to do with like psychology or sociology or things along that line. I think a lot of it will be useful for me down the road with my work in the National Guard." Given the specific subject matter and activist nature of the HT MOOC, it is possible that learner motivations were somewhat unique. Anti-HT volunteers and activists, such as Mimi, appeared to be especially drawn to this particular course:

The reason why I took this MOOC course is because my good friend and I have an organization that brings awareness to sex trafficking in the United States. So, having this opportunity to even delve a little deeper, to understand the global dynamic of it. And I do a lot with just women empowerment. (Mimi, Skype 11, 2015) 
Nearly half of the informants noted that they were motivated by their enjoyment of MOOCs, and many identified this as their primary reason for enrollment. Isabella, Sean, Anne, and Lynn frequently enrolled in MOOCs for fun or as a hobby. Isabella enrolled in up to three MOOCs at a time and engaged in discussions, watched lectures, and read materials rather than, for example, watching television. Anne and Lynn also enjoyed taking more than one MOOC at a time and would not complete it if it was too demanding, serious, or they had an otherwise negative experience. Anne said she liked to learn via MOOCs and did not put pressure on herself to complete them. She said, "I don't push myself. I don't stress out over it."

Several of the informants compared the experience of multiple, simultaneous MOOCs to libraries, buffets, or a Netflix queue, in which they could select what they wanted to learn, absorb the pieces of information they wanted, and then check out of the MOOC when they reached their personal learning goals. Ed equated MOOCs to buffets in Thailand: "It's like a buffet on a timeline. Over here, we have buffets on conveyer belts, and you sit at this place. It's almost like a sushi bar. You sit there, and the food comes by you. Okay? So, it's a matter of what are you in the mood for and how's the timing?"

Discourse analysis also showed that several of the informants described MOOCs mostly in terms of reading, watching, and entertainment. Anne said, "It's a hobby, so I really enjoy putting a class on and learning something."

Informants also identified information retrieval as a key motivator. Blake, Sean, Ed, and Claudia all described how they downloaded MOOC materials to read or listen to at a later time. Claudia planned to develop a website for the Peace Corps' HT prevention program in Moldova and intended to use the course resources to support her work. Claudia explained how MOOCs helped her with information retrieval:

Well, I really wanted to get a lot of resources. There's a lot out there, a lot of books, a lot of journals, a lot of articles - and I do trust that if there is a course and there is a professor behind it, that the professor has chosen particular readings that will be, you know, brand new perspectives. So, at least, you don't have too much searching on your own, where you might just come across something that looks legit and it's not. (Claudia, Skype 3, 2015)

This motivation seems analogous to learners using MOOCs as electronic textbooks as noted by Selingo (2014). Some informants confirmed that they enrolled in the MOOC solely to watch videos or access new resources with no intention of actually completing the course.

Separate from general professional development, three informants enrolled in the MOOC in order to support, even if in a small way, planned career moves. Anne, Mimi, and Torrence had all considered pursuing master's degrees in social justice fields. Anne had evaluated online degree options and looked for ways to engage in anti-HT activism. Mimi viewed the MOOC as an opportunity to see whether she could integrate coursework into her busy life, while Torrence was examining different colleges and their criminal justice programs. 
The least mentioned motivating factors in the study related to social connections and competition. Anne and Mimi both wanted to engage with other learners from around the world. Anne discussed how engaging with diverse MOOC learners broadened her worldview:

Oh, I really love MOOCs in general, and this one because there are people from all over the world. I get a perspective that I can't get just in Indiana. That's a great part of the discussion forums - you hear, you know, people in Africa or eastern Europe or whatever, and they all have their opinions and ideas, and that's really neat to see things from their perspective. (Anne, Skype 1, 2015)

Mimi also identified the desire to learn about her peers' trafficking experiences, perspectives, and anti-HT programs. Regina was the sole informant who described being motivated by competition, specifically, competition with herself. She taught history and reported that the opportunity to test her world history knowledge through a related MOOC exam made her feel competitive.

\section{Success}

Informants were also asked to share their perceptions of what it meant to be successful in a MOOC. All 12 described success in a MOOC as gaining knowledge and understanding course material. Joseph said, "I think success would be understanding the material, and just getting what you can out of that course." Similarly, Blake explained, "For me, if I learn stuff, that's pretty much good enough for me. That's really all I'm in it for is to learn more information, learn new skills." Related to the motivation factor of information retrieval, seven informants mentioned gaining new resources as a core aspect of success. Enjoyment was identified both as a motivator and a criterion for success, as half of the informants stressed the importance of enjoyment to success. Sean discussed how success is tied to personal motivation and how enjoyment is often a goal for taking MOOCs:

I think that that depends on the individual learner because it depends on what your expectations are going in, and it depends on what you as an individual want to get out [of it]. For me, I didn't set high expectations of what I would get out. I knew that I wanted to learn more about the subject and enjoy my time there. And I got out of it what I wanted, so that was, that was it. I think it's different individually for everybody. (Sean, Skype 13, 2015)

Informants such as Anne, Lynn, and Ed compared their enjoyment level with MOOCs to that of an engaging book.

For five informants, success in a MOOC meant expanding their worldviews; three informants wanted to become informed citizens on a topic. The HT MOOC had a "Share Your Story" discussion forum that encouraged learners to share their personal experiences with HT, and some interview informants specifically mentioned that this forum expanded their views of the topic which, to them, meant success. Regina highlighted how success was related to being able to apply what she learned in a MOOC to her everyday life and to better understand the issues facing her community. She elaborated that success: 
How much takeaway that I have, how much better I understand what the current events are. Can I speak with authority to my legislator? Do I have something here where I can write a letter to my congressman? And I think that I do. I think that was one of the benefits of this particular MOOC. (Regina, Skype 12, 2015)

These responses also speak to the open nature of MOOCs and the global conversations that their massive numbers encourage.

For a single informant, Mimi, the development of new relationships and connections and earning recognition for her anti-trafficking organization were key to her perceptions of success. Mimi established a relationship over email with the MOOC instructor, with whom she shared perspectives and resources about trafficking. The instructor also shared Mimi's Public Service Announcement (PSA) in the week four course materials. While Mimi was the only informant to mention new relationships and recognition as a part of her definition of success, social engagement and diverse viewpoints were common threads among those informants who noted the value they placed on learning from fellow students from around the world.

\section{Completion}

Of the initial fourteen learners who agreed to participate in the study, half did not complete the MOOC, meaning they did not meet the course requirements and earn a Statement of Accomplishment.

Table 1. Informants' MOOC completion

\begin{tabular}{|c|c|c|c|c|c|c|}
\hline Pseudonym & Education & Location & Quiz 1 & Quiz 2 & $\begin{array}{l}\text { PSA } \\
\text { Assignment }\end{array}$ & $\begin{array}{l}\text { Statement of } \\
\text { Accomplishment }\end{array}$ \\
\hline Anne & Bachelor's & Indiana & Yes & No & No & No \\
\hline Blake & Bachelor's & Utah & Yes & $\begin{array}{l}\text { Yes }(2 \\
\text { attempts) }\end{array}$ & No & No \\
\hline Claudia & Master's & Moldova & $\begin{array}{l}\text { Yes }(2 \\
\text { attempts) }\end{array}$ & Yes & Yes & Yes \\
\hline Elizabeth & Bachelor's & Washington & Yes & Yes & Yes & Yes \\
\hline $\mathrm{Ed}$ & Bachelor's & Thailand & No & No & No & No \\
\hline *Fernando & Bachelor's & Guatemala & Yes & Yes & No & No \\
\hline Isabella & Master's & China & $\begin{array}{l}\text { Yes ( } 2 \\
\text { attempts) }\end{array}$ & Yes & Yes & Yes \\
\hline Joseph & Bachelor's & Michigan & $\begin{array}{l}\text { Yes }(2 \\
\text { attempts) }\end{array}$ & Yes & Yes & Yes \\
\hline *Lauren & $\begin{array}{l}\text { Some } \\
\text { college }\end{array}$ & Louisiana & Yes & No & No & No \\
\hline Lynn & Bachelor's & Indiana & Yes & $\begin{array}{l}\text { Yes (2 } \\
\text { attempts) }\end{array}$ & Yes & Yes \\
\hline Mimi & Bachelor's & New Jersey & Yes & Yes & Yes & Yes \\
\hline Regina & Master's & Indiana & $\begin{array}{l}\text { Yes }(2 \\
\text { attempts) }\end{array}$ & Yes & Yes & Yes \\
\hline Sean & Master's & Pennsylvania & Yes $(4$ & Yes & No & No \\
\hline
\end{tabular}




\begin{tabular}{llllll} 
& & attempts) & & \\
Torrence & Bachelor's Michigan & No & No & No & No (un-enrolled) \\
\hline
\end{tabular}

*Fernando and Lauren did not participate in post-interviews.

The twelve informants who completed post-interviews were asked how they defined completion of the MOOC. The informants made a distinction between success in the MOOC and actually completing the MOOC. Ten of the twelve informants defined completion as completing course requirements and earning the Statement of Accomplishment. Joseph defined completion as "[C]ompleting the class! [laughs] Getting the quizzes, getting the, uh, PSA in and graded for the other people. That's what was outlined for us as to what we needed to do for the class, and it felt like that was completion." Success was defined in more personal terms while completion was defined as satisfying the requirements of the course and instructor. For instance, Elizabeth explained her perceived differences between success and completion:

I think I probably come at it from a unique perspective in that I'm a stay at home mom, and I take courses that interest me because they interest me. Because I believe that you should never stop learning, and so for me success is: Did I actually cover all the material? - because with a toddler that's not always easy. And then, success is, did I actually learn something from it? I would say that is a unique perspective in that I'm not looking for a grade out of it. I'm not looking for a GPA. I'm not looking for continuing ed credits. I'm not looking for any of those more typical academic accouterments that come from taking a class. I want to learn something about something I'm interested in. If I can finish the material, and if I've learned something, then it's a success. (Elizabeth, Skype 4, 2015)

Ed differentiated between completion and success by highlighting that while completion meant fulfilling course requirements, at his age and stage of learning, his goal for enrollment and participation in MOOCs was not necessarily to complete them. Five of the informants, including Isabella, Lynn, and Ann, who take MOOCs as a hobby, highlighted a personal sense of satisfaction as a component of their definition of completion. Lynn did not focus on meeting course requirements as part of her definition of MOOC completion:

It's something that I feel proud of. I mean, it's something that's completely personal and just for me. I don't have to do it for anyone else or to get any sort of, you know degree. It's just for me, and it's something that I enjoy. (Lynn, Skype 10, 2015)

Five informants also identified downloading MOOC resources as a part of completing a MOOC. Blake, Anne, and Sean connected completion to downloading these resources to digest, gain new perspectives, and support their personal learning efforts, whether they were lifelong or related to seeking a degree. To Anne, completion was more connected to gaining new resources, watching video lectures, and enjoyment:

For me, it's to watch all the video lectures. In my head, that's what it is. But, I really do appreciate the extra, I mean, I like having the extra resources, so I can go read some books or look up what else that guy they interviewed has done or something. (Anne, Skype 1, 2015) 
Regina, a teacher in an alternative school, was the only informant to target enhanced professional authority as key to completing the MOOC, as she took MOOCs to brush up on topics, learn more about them, and inform her teaching about them.

Discussion regarding the purpose of credentials varied, although the majority of informants identified earning the Statement of Accomplishment as significant to their definition of completion. Torrence was interested in Coursera's "Signature Track" program that obtained credentials to demonstrate professional development or apply toward graduate degree work. Informants such as Sean wondered about the utility of a Statement of Accomplishment in terms of its value to employers or inclusion on his cv:

This is going to be partially up to the individual. Like, how much effort or merit do you hold in having that, um, digital certificate of completion? But, I often wonder can I put that on my cv? Will that matter when I'm job-hunting later? Or, um, will anyone care? Will I use this material ever? I wonder that, too. Um, so, I don't know. I think partially, it's individually based. I put the last one on my cv, and if I had completed this one, throughout, and got the certificate, I would put that on my cv, too. Um, and also, it depends on if it's related to your career or not, I guess. (Sean, Skype 13, 2015)

Others clearly valued the Statement of Accomplishment; Elizabeth, Lynn, Joseph, Blake, and Isabella planned to print out their Statements or save them online as a record of their achievement. Claudia and Mimi intended to include the Statement on their resumes, while Regina framed hers and displayed them in her classroom.

I can tell you exactly what I do with them. I print them out, and I put them in an $8 \times 10$ frame, and I put them on the chalkboard of my classroom, and I say, "This is an example of lifelong learning."(Regina, Skype 12, 2015)

\section{Barriers}

While this study did not begin with a specific research question about barriers to MOOC success and completion, barriers emerged as a theme during inductive coding. In this study, all 12 informants described time and the course design as the biggest barriers to MOOC completion. Informants mentioned that while they valued MOOCs for professional development and lifelong learning, they had full lives with other priorities such as family, career, school, and volunteerism. So, when their lives became hectic, MOOC participation was assigned a lower priority. For example, Ed enrolled in the HT MOOC with plans to participate and complete it, but this was prevented by assuming a new role in his local Rotary Club chapter and his efforts to help increase sales for a businessman in Thailand who donated a portion of his profits to antitrafficking efforts. Ed explained not having time for the HT MOOC:

What happened in this case was the MOOC started the week I was in Cambodia. So, I came back, I was a week behind in a four-week course. And then, all of a sudden, out of, I guess it's not really out of the blue, but all of the sudden, I ended up being the secretary of this little Rotary Club and was spending a lot of hours trying to figure out what that was about. (Ed, Skype 6, 2015) 
The informants also highlighted course design as a core factor in their decisions to complete a MOOC or not. All had individual motivations for taking the HT MOOC and expectations about how the MOOC would be designed. Elizabeth felt that the videos in the HT MOOC were too short compared to other MOOCs she had taken. Isabella and Anne also noted how the design was different than other MOOCs they had taken because it had shorter videos and a stronger focus on discussion. Criticism of the course design was evident in some of the discussion threads. Sean, Regina, and Joseph all expected more content and information from the instructor and felt that they did not necessarily build upon their existing knowledge regarding the topic. Expectations for the course design, as well as whether those expectations were met, were clearly related to whether or not learners participated in and completed the course. In contrast to the learners who preferred a course design with lengthy lecture videos, a plethora of resources, and limited discussion, learners such as Claudia, Lynn, and Mimi enjoyed reading and engaging in discussion boards, participating in peer-grading, as well as interacting with the instructor when possible. These different expectations for course content, design, and delivery seem to reflect the differences in cMOOC (relational learning) and xMOOC (self-paced) approaches.

For six of the informants, frequent enrollment in MOOCs was a barrier to completing them. For example, Blake described how he would sign up for several MOOCS at a time. He sometimes learned new concepts and downloaded materials, but often did not participate in or complete the MOOCs:

Sometimes, I get really into the MOOC I'm doing, but then, I have to force myself to stop because I know that I have other homework that is for an actual grade that is going to impact an actual degree. So, I have to tear myself away from Coursera and go work on that. (Blake, Skype 2, 2015)

Anne described how the MOOC's design, her frequent MOOCing, and lack of interest as a combination of factors that prevented her from completing certain MOOCs:

Either it's too difficult, and it's way over my head. Or it's too easy, and I already know all of this. Or, for me, because I usually have several going on, it's just I'm choosing to not do this one because these other ones that are going on at the same time are more interesting to me. (Anne, Skype 1, 2015)

Life circumstances also posed a barrier to course completion for four of the informants. For example, Torrence planned to complete the MOOC but a severe storm knocked out power to his home and business for two days and also damaged his rental property. Three of the informants described a lack of interest in the topic as a barrier to whether or not a MOOC was completed. The free nature of learning through MOOCs was also highlighted as a possible barrier by two of the informants, including Torrence:

I think that's like another part to it, like you're not as invested, like as if this were a college course that you were paying for. You don't have that, that financial obligation like, 'Oh, I have to complete this. Oh, I can just go, click, un-enroll.' It's not as big of a deal. (Torrence, Skype 14,2015). 
Finally, two informants mentioned that if the MOOC was not enjoyable, that served as a barrier to completion. This could also be related to the discussion on the quality of the course design as well as some informants' lack of interest in the topic.

\section{Discussion and Implications}

Much of the debate about MOOCs centers on identifying their purpose and potential for and within higher education. Quantitative data have demonstrated MOOC learners are typically well-educated adults who often do not complete courses as defined by instructor and institution parameters. However, a sound systematic instructional design approach emphasizes gaining a strong understanding of one's target learners through a needs assessment, in order to create better learner-centered instruction and environments. Using virtual ethnographic methods, this study aimed to demystify the adult learner experience in MOOCs, thus creating a deeper understanding of MOOC participants. The result was a richer understanding of adult learners' motivations, perceptions of success and completion, and perceived barriers to completion. The research provides a first step toward describing the diversity and complexity of adult learners' MOOC learning paths.

To gain a more conceptual understanding of the adult learner MOOC experience, we organized the results into a framework that illustrated the similarities and differences among the informants' MOOC experiences and perceptions of motivation, success, and completion (Figure 1). An additional theme, barriers to MOOC success and completion, also emerged and is included in this framework. Instructor, social, and cognitive presences are at the center of the framework because, based on instructional design models for effective distance education, those presences are believed to occur in effective online Communities of Inquiry (CoI) (Blackmore, 2010; Garrison, Anderson, \& Archer, 2010; Gunawardena \& Zittle, 1997; Richardson \& Swan, 2003). Instructor, social, and cognitive presences also emerged in the learners' MOOC experiences. For instance, motivation for social connection is linked to teaching and social presences; perceptions of understanding new material as a success is linked to cognitive presence, and goals of watching lecture videos linked to teacher presence.

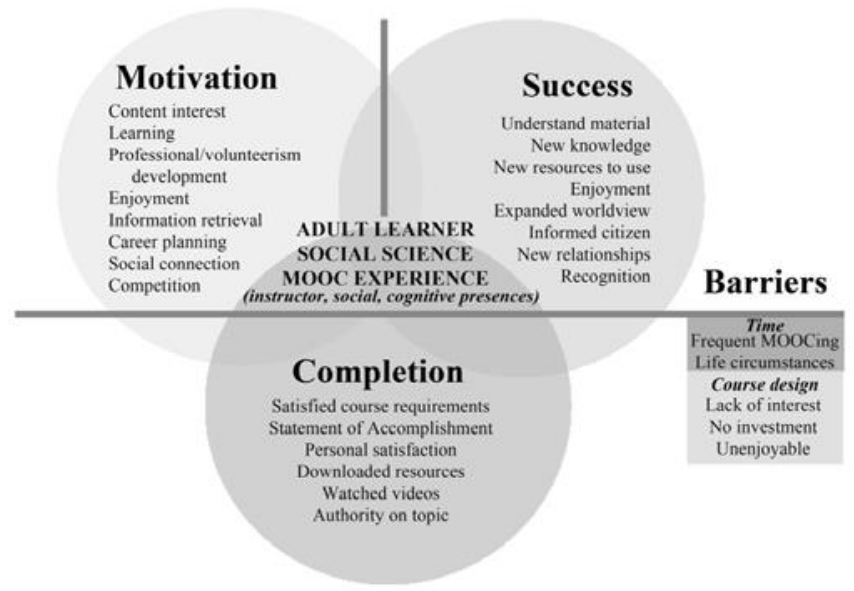

Figure 1. Conceptual Framework of Adult Learner Social Science MOOC Experiences 
While further examination of the framework is needed in additional contexts, instructional designers should consider the conceptual framework when strategically designing MOOCs that are responsive to adult learners' needs. We also recommend MOOCs be redesigned to become more learner centered. As the results of this study showed, learners have a variety of paths and expectations within a MOOC. While some learners value discussion boards and instructor engagement, others prefer to have limited interaction and focus solely on the course content via videos, readings, and assignments. The results of this study support recommendations from prior research suggesting that cMOOC (connectivist) and xMOOC (selfpaced) instructional design approaches be combined to better address adult learners' diverse learning needs and goals (Crosslin \& Dellinger, 2015; Dubosson \& Emad, 2015). Currently, selfdirected learning and self-determination (Cerone 2008; Theunissen \& Stubbé, 2014) persist in MOOCs, as adult learners have varied reasons for participating in the massive courses such as topic interest, knowledge advancement, career changes, and relationship formation.

Informants in this study tended to equate MOOC success with personal knowledge gain and enjoyment and MOOC completion with both personal satisfaction and course requirement fulfillment. Multiple informants who took several MOOCs at the same time viewed MOOC enrollment similar to lining up multiple videos in a Netflix queue. It appears that as a result of this learner phenomenon, MOOC platform provider Coursera has rolled out a new month-bymonth payment model similar to the Netflix subscription model (Willerer, 2016). The company's chief product officer wrote a blog post describing the option to make monthly payments for Cousera "specializations," a set of content-related courses, instead of paying on a per course basis. Coursera stated that the subscriptions would make MOOCs more flexible for enrollees' schedules and personal learning by providing simultaneous access to content across courses.

In open learning environments, adult learners are capable of setting their own learning goals and defining their own standards for course success and completion. This conflicts with many MOOC designs, which focus on meeting course requirements to earn certificates and calculating course completion rates based on number of earned certificates. In contrast, Koller et al. (2013) suggested that learners' intentions, rather than completion, should be considered in order to offer a clearer measure of the success of a specific MOOC. The results of this study support the potential for allowing learners to define personal parameters and requirements for success and completion based on their individual motivations and available time for committing to a MOOC.

Adult learning theory, self-directed learning (SDL), self-determination (SDT), and motivation posit that adults have the capacity to be self-aware during their learning processes (Cerone 2008; Hartnett et al., 2011). The informants in this research definitely had an awareness of their learning purposes, processes, and goals within the HT MOOC. SDL theory states that adult learners are able to self-assess their own learning on the path to meeting their goals (Hiemstra, 1994). However, current MOOCs often do not provide the opportunity for learners to assess their own progress in relation to their personal goals. The patterns of similarities and differences across adult learners' MOOC motivations, perceptions of success, and completion illustrate that a one-size-fits-all approach for delivering instruction on a massive scale to learners around the world is not feasible and will not be successful. It is important for MOOCs to be dynamic and flexible, not fixed and stagnant. The results of this study suggest that MOOCs must 
be responsive to learners' motivations and goals by offering a variety of entry points and assessments that go beyond completion, to measure intention and perceptions of learning success. An opportunity exists to develop and deploy Personalized Integrated Educational Systems (PIES), as conceptualized by Reigeluth, Watson, and Watson (2012), to address the complexities of the adult learner experience. The PIES concept calls for an open learning system that is fluid, flexible, and customizable for learners and instructors. This includes customizing learning goals and assessment.

A final implication of this study is the potential of MOOCs for volunteerism development, social justice education, and attitudinal change. Nine of the 12 informants in this research were connected to various anti-trafficking volunteer organizations. Further, their primary reasons for enrolling in the HT MOOC were to further their understandings of the issue in order to apply their new knowledge to their volunteer efforts. Observations of the HT MOOC showed that the instructor and instructional designer had an overarching goal to raise HT awareness through a global learning platform and to impact students' attitudes about the controversial topic.

The majority of current research and discussion related to MOOCs focuses on potential uses of MOOCs for (a) introducing high school students to college and higher education institutions (Horn, 2014; Najafi, Evans, \& Federico, 2014), (b) using blended-learning approaches for current college students (Kolowich, 2013c), and (c) offering MOOCs for degree attainment or professional development (Stephens \& Jones, 2014). This study revealed that another reason adult learners participate in MOOCs is to advance volunteerism and social justice efforts in order to engage in public knowledge building about controversial issues. Transformational learning theory supports this notion that adult learners can change their thoughts and behaviors as a result of participation in educational programs (Merriam \& Bierma, 2013; Hoggan, 2016). In the case of the HT MOOC, informants' awareness and perceptions of modern day slavery shifted, as participants considered how to make a positive impact within their own spheres of influence. Several informants in this study described not only a desire to increase their personal knowledge, but to also actively engage in bettering the world around them. As this study demonstrated, MOOCs developed and offered in the social sciences and humanities have the potential to mobilize both individual learners and entire communities, and to democratically and critically engage in controversial issues with the intent to expand understanding, change attitudes, and promote positive change.

\section{Limitations and Future Research}

The limitations of this study include the small, voluntary sample of research informants, the short duration of the study, and potential researcher bias. Learners in this study volunteered to participate via an online survey and self-described their demographics and educational levels. Further, informants in this study were between the ages of 25 to 70 with bachelors' and master's degrees, which could have led to a narrow or inaccurate view of the adult learner MOOC experience. The HT MOOC lasted for only four weeks, resulting in a very fast-paced timeframe for the study. As such, researchers spent a limited amount of time in the field making observations and interacting with informants. In general, Hine (2000) recommended that virtual ethnographers spend a substantial amount of time in the field to collect rich, thorough data. 
Finally, in qualitative inquiry, the researchers serve as the research instrument. While reflexive journaling, informant interviews, data triangulation, and member checking were used, the potential still remains for researcher bias.

Additional research on MOOCs is needed. First, the conceptual framework for the adult learner social science MOOC experience presented in this article requires further application across diverse MOOC environments and learner populations to determine if it is a viable framework for instructional designers and instructors to consider when developing and implementing customizable learner-centered MOOCs. Second, there is a need to design technologies, such as PIES (Reigeluth, Watson, \& Watson, 2012), which support a MOOC dashboard where adult learners can self-determine their personal motivations and goals for success and completion. Third, future research should also examine MOOC design and conditions for engaging adults in transformational learning. Hoggan's (2015) definition of transformation, criteria, and typology should be applied to MOOCs to determine whether or not the courses can spur adults to make life and societal changes which might positively impact social justice issues. Additional research is currently underway to investigate how MOOCs can be intentionally designed for attitude change instruction (Watson, Kim, \& Watson, 2016; Watson, Watson, Richardson, \& Loizzo, 2016). Finally, the capacity for MOOCs to engage adults in customizable learning experiences for attitude change and transformation around social justice topics should be further explored.

\section{References}

Bell, F. (2011). Connectivism: Its place in theory-informed research and innovation in technology-enabled learning. The International Review of Research in Open and Distance Learning, 12(3), 98-118. Retrieved from http://www.irrodl.org/index.php/irrodl/article/view/902

Blackmore, C. (Ed.). (2010). Social learning systems and communities of practice. London, UK: Springer. http://dx.doi.org/10.1007/978-1-84996-133-2

Broad, K. L., \& Joos, K. E. (2004). Online inquiry of public selves: methodological considerations. Qualitative Inquiry, 10(6), 923-946. http://dx.doi.org/10.1177/1077800404265720

Cercone, K. (2008). Characteristics of adult learners with implications for online learning design. AACE Journal, 16(2), 137-159.

Clarà, M., \& Barberà, E. (2013). Learning online: Massive open online courses (MOOCs), connectivism, and cultural psychology. Distance Education, 34(1), 129-136. http://dx.doi.org/10.1080/01587919.2013.770428

Coursera Blog (2016). Retrieved from < https://blog.coursera.org/post/137649201147>.

Crosslin, M. \& Dellinger, J. (2015). Lessons learned while designing and implementing a multiple pathways xMOOC + cMOOC. In D. Slykhuis \& G. Marks (Eds.), Proceedings 
of Society for Information Technology \& Teacher Education International Conference 2015 (pp. 250-255). Chesapeake, VA: Association for the Advancement of Computing in Education (AACE). Retrieved from https://www.learntechlib.org/p/149999

de Barba, P. G., Kennedy, G. E., \& Ainley, M. D. (2016). The role of students' motivation and participation in predicting performance in a MOOC. Journal of Computer Assisted Learning, 32, 218-231.

Denzin, N. K. (1989). The research act: A theoretical introduction to sociological methods (3rd ed.). Englewood Cliffs, NJ: Prentice Hall.

Dubosson, M., \& Emad, S. (2015). The forum community, the connectivist element of an xMOOC. Universal Journal of Educational Research, 3(10), 680-690.

Esposito, A. (2012). Research ethics in emerging forms of online learning: Issues arising from a hypothetical study on a MOOC. Electronic Journal of E-Learning, 10(3), 315-325. Retrieved from http://www.eric.ed.gov/contentdelivery/servlet/ERICServlet?accno=EJ985433

Garrison, D. R., Anderson, T., \& Archer, W. (2010). The first decade of the community of inquiry framework: A retrospective. Internet and Higher Education, 13(1), 5-9. http://dx.doi.org/10.1016/j.iheduc.2009.10.003

Gerber, H. R., Abrams, S. S., Curwood, J. S., Magnifico, A. M. (2017) Conducting qualitative research of learning in online spaces. Thousand Oaks, California: Sage Publications.

Gose, Ben (2012). 4 massive open online courses and how they work. The Chronicle of Higher Education: Online Learning, 59(6), B8-B11.

Gunawardena, C. N., \& Zittle, F. J. (1997). Social presence as a predictor of satisfaction within a computer-mediated conferencing environment. The American Journal of Distance Education, 11(3), 8-26. http://dx.doi.org/10.1080/08923649709526970

Haber, J. (2014). MOOCs. Cambridge, MA: MIT Press.

Hartnett, M., St. George, A. S., \& Dron, J. (2011). Examining motivation in online distance learning environments: Complex, multifaceted and situation-dependent. The International Review of Research in Open and Distributed Learning, 12(6), 20-38.

Hesse-Biber, S. N. (2017). The practice of qualitative research. Thousand Oaks, CA: Sage Publications.

Hew, K. F., \& Cheung, W. S. (2014). Students' and instructors' use of massive open online courses (MOOCs): Motivations and challenges. Educational Research Review, 12, 45-58.

Hiemstra, R. (1994). Self-directed learning. In Rothwell, W. J. \& Sensenigh, K.J. (Eds.), The sourcebook for self-directed learning (9-17). Amherst, MA: HRD Press, Inc. 
Hilton, III, J., Wiley, D., Stein, J., \& Johnson, A. (2010). The four 'R's of openness and ALMS analysis: Frameworks for open educational resources. Open Learning, 25(1), 37-44. http://dx.doi.org/10.1080/02680510903482132

Hine, C. (2000). Virtual ethnography. London, UK: Sage Publications.

Ho, A. D., Reich, J., Nesterko, S. O., Seaton, D. T., Mullaney, T., Waldo, J., \& Chuang, I. (2014). HarvardX and MITx: The first year of open online courses, Fall 2012-Summer 2013 (HarvardX and MITX Working Paper No. 1). Retrieved from http://ssrn.com/abstract=2381263

Hollands, F. M., \& Tirthali, D. (2014). Why do institutions offer MOOCs?. Online Learning, 18(3), 1-19.

Hoggan, C. D. (2016). Transformative learning as a metatheory: Definition, criteria, and typology. Adult Education Quarterly: A Journal of Research and Theory,66(1), 57-75.

Horn, M. B. (2014). MOOCs for high school. Education Next, 14(3), 82-83. Retrieved from http://educationnext.org/moocs-high-school/

Jenkins, R. (2013). Who is driving the online locomotive? The Chronicle of Higher Education. Retrieved from http://chronicle.com/article/Who-Is-Driving-the-Online/140505/

Jordan, K. (2014). Initial trends in enrolment and completion of massive open online courses. International Review of Research on Open and Distance Learning, 15(1), 133-160. Retrieved from http://www.irrodl.org/index.php/irrodl/article/view/1651

Kennedy, J. (2014). Characteristics of massive open online courses (MOOCs): A research review, 2009-2012. Journal of Interactive Online Learning, 13(1).

Khalil, H., \& Ebner, M. (2014). MOOCs completion rates and possible methods to improve retention - A literature review. In J. Herrington, J. Viteli, \& M. Leikomaa (Eds.), Proceedings of the World Conference on Educational Multimedia, Hypermedia and Telecommunications (pp. 1305-1313). Chesapeake, VA: Association for the Advancement of Computing in Education (AACE).

Kizilcec, R. F., \& Schneider, E. (2015). Motivation as a lens to understand online learners: Toward data-driven design with the OLEI scale. ACM Transactions on Computer-Human Interaction (TOCHI), 22(2), 6.

Koller, D., Ng, A., Chuong, D., \& Zhenghao, C. (2013). Retention and intention in massive open online courses: In depth. EDUCAUSE Review Online, 48(3), 62-63. Retrieved from http://www.educause.edu/ero/article/retention-and-intention-massive-open-onlinecourses-depth-0 
Kolowich, S. (2013a). San Jose State U. puts MOOC project with Udacity on hold. The Chronicle of Higher Education. Retrieved from http://chronicle.com/article/San-JoseState-U-Puts-MOOC/140459/

Kolowich, S. (2013b). A university's offer of credit for a MOOC gets no takers. The Chronicle of Higher Education. Retrieved from http://chronicle.com/article/a-universitys-offer-ofcredit/140131/

Kolowich, S. (2013c). A Truce on the tech front at San Jose State. The Chronicle of Higher Education, 60(13), A21-A23.

Korn, M., \& Levitz, J. (2013). Online courses look for a business model: Free classes, open to the masses, seek to generate revenue from content licensing, exams or job-referral services. The Wall Street Journal, B8. Retrieved from http://online.wsj.com/news/articles/SB10001424127887324339204578173421673664106

Lewin, T. (2013). After setbacks, online courses are rethought. The New York Times, 10. Retrieved from http://www.nytimes.com/2013/12/11/us/after-setbacks-online-coursesare-rethought.html

Liyanagunawardena, T. R., Adams, A. A., \& Williams, S. A. (2013). MOOCs: A systematic study of the published literature 2008-2012. The International Review of Research in Open and Distance Learning, 14(3), 202-227.

Lombardi, M. M. (2013). The inside story: Campus decision making in the wake of the latest MOOC tsunami. Journal of Online Learning and Teaching, 9(2). Retrieved from http://jolt.merlot.org/vo19no2/lombardi_0613.htm

Luberecki, B. (2015). Massive open online courses (MOOCs) can help you achieve the next step in your career. The Washington Post. Retrieved from https://www.washingtonpost.com/express/wp/2015/09/14/massive-open-online-coursesmoocs-can-help-you-achieve-the-next-step-in-your-career/

McAuley, A., Stewart, B., Siemens, G., \& Cormier, D. (2010). The MOOC model for digital practice. elearnspace.org. Retrieved from http://www.elearnspace.org/Articles/MOOC_Final.pdf

Nesterko, S. O., Seaton, D. T., Kashin, K., Han, Q., Reich, J., Waldo, J., .. . Ho, A. D. (2014a). Education levels composition. HarvardX Insights. Retrieved from http://harvardx.harvard.edu/harvardx-insights/education-levels-composition

Najafi, H., Evans, R., \& Federico, C. (2014). MOOC integration into secondary school courses. International Review of Research in Open \& Distance Learning, 15(5), 306-322. 
Nesterko, S. O., Seaton, D. T., Kashin, K., Han, Q., Reich, J., Waldo, J., .. . Ho, A. D. (2014b). World map of education composition. HarvardX Insights. Retrieved from http://harvardx.harvard.edu/harvardx-insights/world-map-education-composition

Oakley, B., Poole, D., \& Nestor, M. (2016). Creating a sticky MOOC. Online Learning, 20(1), 112.

Pappano, L. (2012). The year of the MOOC. The New York Times, 2(12). Retrieved from http://www.nytimes.com/2012/11/04/education/edlife/massive-open-online-courses-aremultiplying-at-a-rapid-pace.html

Park, J.-H., \& Choi, H. J. (2009). Factors influencing adult learners' decision to drop out or persist in online learning. Educational Technology \& Society, 12(4), 207-217.

Reigeluth, C. M., Watson, W. R., \& Watson, S. L. (2012). Personalized integrated educational systems: Technology for the information-age paradigm of education in higher education. In S. P. Ferris (Ed.), Teaching and learning with the net generation (pp. 41-60). Hershey, PA: IGI Global. http://dx.doi.org/10.4018/978-1-61350-3478.ch003

Richardson, J., \& Swan, K. (2003). Examining social presence in online courses in relation to students' perceived learning and satisfaction. Journal of Asynchronous Learning Networks, 7(1), 68-88.

Roberts, P. (2015). Paulo Freire and utopian education. Review of Education, Pedagogy \& Cultural Studies, 37(5), 376-392.

Rodriguez, C. O. (2012). MOOCs and the AI-Stanford like courses: Two successful and distinct course formats for massive open online courses. European Journal of Open, Distance and E-Learning. Retrieved from http://www.eurodl.org/?p=archives $\&$ year $=2012 \&$ halfyear $=2 \&$ article $=516$

Schunk, D. H., Pintrich, P. R., \& Meece, J. L. (2008). Motivation in education: Theory, research, and applications. Columbus, $\mathrm{OH}$ : Pearson Merrill Prentice Hall.

Schwandt, T. A. (2015). The SAGE dictionary of qualitative inquiry. Fourth edition. Thousand Oaks, California: Sage Publications.

Selingo, J. J. (2014). MOOC U: Who is getting the most out of online education and why [EBook]. New York, NY: Simon \& Schuster.

Siemens, G., \& Conole, G. (Eds.). (2011). Special issue-Connectivism: Design and delivery of social networked learning. International Review of Research in Open \& Distance Learning, 12(3), I-IV. 
Stephens, M. M., \& Jones, K. L. (2014). MOOCs as LIS professional development platforms: Evaluating and refining SJSU's first not-for-credit MOOC. Journal of Education for Library \& Information Science, 55(4), 345-361.

Stubbé, H. E., \& Theunissen, N. C. (2008, January). Self-directed adult learning in a ubiquitous learning environment: A meta-review. In Proceedings of the First Workshop on Technology Support for Self-Organized Learners (pp. 5-28).

Theunissen, N., \& Stubbé, H. (2014). iSELF: The development of an internet-tool for selfevaluation and learner feedback. Electronic Journal of e-Learning, 12(4), 313-325. R

Thille, C., Mitchell, J., \& Stevens, M. (2015). What we've learned from MOOCs. Inside Higher Ed. Retrieved from https://www.insidehighered.com/views/2015/09/22/moocs-are-nopanacea-they-can-help-improve-learning-essay

Tschofen, C., \& Mackness, J. (2012). Connectivism and dimensions of individual experience. International Review of Research in Open \& Distance Learning, 13(1), 124-143.

Udacity. (2015). Retrieved from https://www.udacity.com/

Velestianos, G. (Ed.) (2013). Learner experiences with MOOCs and open online learning (pp. 10-13). Hybrid Pedagogy. Retrieved from http://hybridpedagogy.github.io/LearnerExperiencesInMOOCs/

Watson, W. R., Kim, W., \& Watson, S. L. (2016). Learning outcomes of a MOOC designed for attitudinal change: A case study of an Animal Behavior and Welfare MOOC. Computers \& Education, 96, 83-93.

Watson, S. L., Loizzo, J., Watson, B. R., Mueller, C., Lim, J. \& Ertmer, P. A. (in press). Instructional design and facilitation of a human trafficking MOOC: A case study of attitudinal change. Educational Technology Research and Development.

Watson, S. L., Watson, W. R., Richardson, J., \& Loizzo, J. (2016). Instructor's Use of Social Presence, Teaching Presence, and Attitudinal Dissonance: A Case Study of an Attitudinal Change MOOC. The International Review of Research in Open and Distributed Learning, 17(3).

Willerer, T. (2016, October). Introducing subscriptions for specializations. Coursera Blog. Retrieved from http://coursera.tumblr.com/post/152555853192/introducingsubscriptions-for-specializations

Zutshi, S., O'Hare, S., \& Rodafinos, A. (2013). Experiences in MOOCs: The perspective of students. American Journal of Distance Education, 27(4), 218-227. 